\title{
PLASTIC WELDING PROCESS SIGNATURE
}

\author{
Marcelo Cavaglieri ${ }^{1}$, Sergio Villalva ${ }^{1}$, Filipe Figueiredo ${ }^{1}$, Fabiano Cardia ${ }^{1}$ Geraldo dos Reis ${ }^{1}$ \\ ${ }^{1}$ Magneti Marelli Sistemas Automotivos \\ E-mails: marcelo.cavaglieri@ magnetimarelli.com, sergio.villalva@msxi.com.br, \\ filipe.figueiredo@magnetimarelli.com, fabiano.cardia@magnetimarelli.com, \\ geraldo.reis@magnetimarelli.com
}

\begin{abstract}
This paper describes a method developed to control the ultrasonic welding quality applied on fuel rails of internal combustion engines. This method consists in monitoring some physical phenomena involved in the welding process, as vibration amplitude, weld energy and process duration. Based in statistical analyses, durability and thermal ageing tests performed with a great population of manufactured parts, it was possible to classify some welding parameters and build a real time filter, able to segregate poor quality parts in less than one second, right after process has finished. In this way, it is possible to eliminate nonconforming parts before performing the functional tests in the assembling line, reducing the process cycle time and saving resources. Based on the observation of rejected and approved parts on the functional tests, patterns could be created for the welding quality. Therefore, the measured parameters indicate the weld characteristics, corresponding to its signature, which can be compared to the established patterns.
\end{abstract}

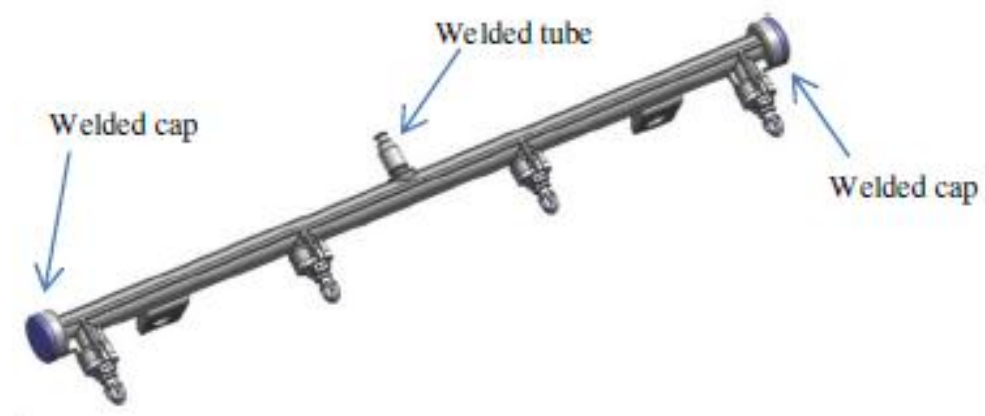

Figure 1 - Assembled mini fuel rail [6].

\section{INTRODUCTION}

During some industrial processes, it is necessary to evaluate the quality of the production line, classifying and segregating bad parts with reliable efficiency. It is quite important when the component involves equipment or people safety. Due to the increase of plastic parts usage in vehicles, mainly in security and critical items, these processes must be more and more reliable. This is the case of the welded fuel rail plastic parts, which should be very well attached to guaranty no leaks in all vehicle conditions during its work life. 
The above component, shown on Figure 1, is the Mini Fuel Rail (MFR), manufactured in thermoplastic (PA66 + 30\%FG). The MFR is one of the components responsible to inject and equally distribute gasoline during the cold start period, as part of Cold Start System (CSS).

As mentioned, the complete fuel rail is part of CSS that is composed in its whole by gasoline reservoir with a small pump, hoses that conduct gasoline up to the Fifth injector, which is connected to the MFR inlet, assembled with four mini injectors. The MFR makes the right introduction of fuel near to the admission valves.

The MFR is attached to the intake manifold in a way that can easily reach its function, see on Figure 2 and Figure 3.

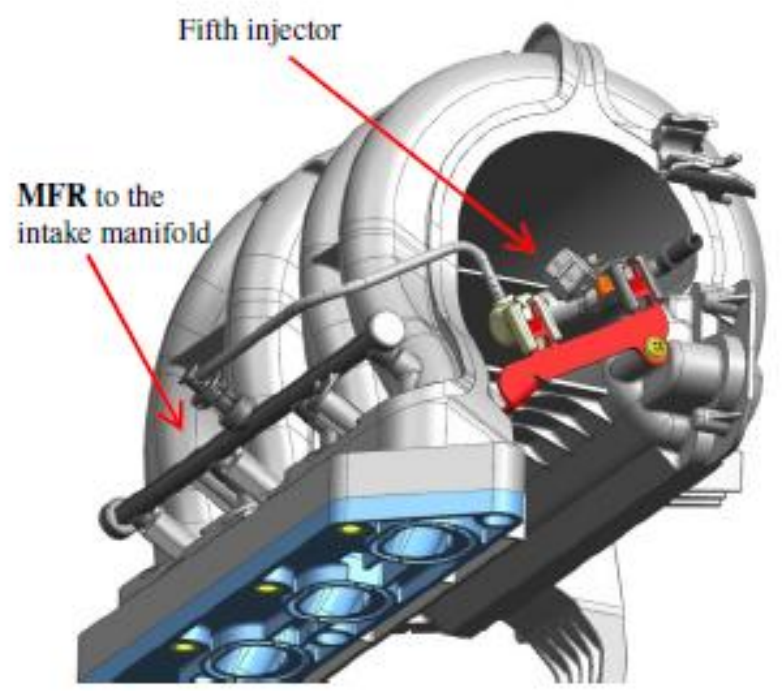

Figure 2 - Cold start system (CSS) on intake manifold [6].

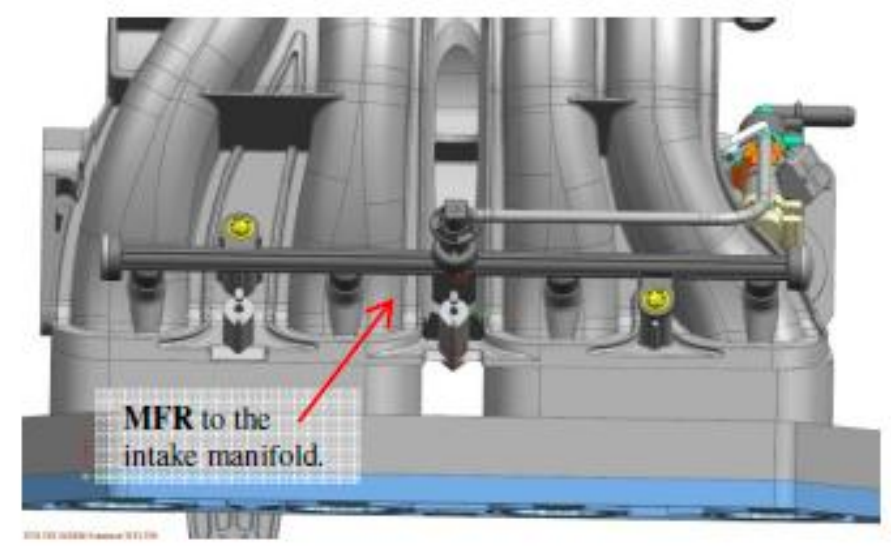

Figure 3 - MFR positioned on intake manifold [6].

As it can be expected, for the MFR ensures its purpose correctly, its components must be free of leaks. So, these parts are critical, because if the welding were not well-done the complete fuel rail will not be able to perform its function safely. Based on these requirements it was developed a procedure to detect the welding quality as soon as it has done. It is a kind of an on line filter, installed beside of ultrasonic welding equipment that analyzes the energies 
which flows through the parts, measuring the energy differences, what makes possible to determine the weld quality.

\section{CONCEPT AND APPROACH}

The complete procedure comprehends communication with the equipment which makes the ultrasonic welding. This communication acquires the values generated to make the parts friction, then, the signal processing, coming from the vibration response, supplies a set of information about the parts contacts, the final parts interface and the overall welding quality. Find on Figure 4 a block diagram about the filter concept.

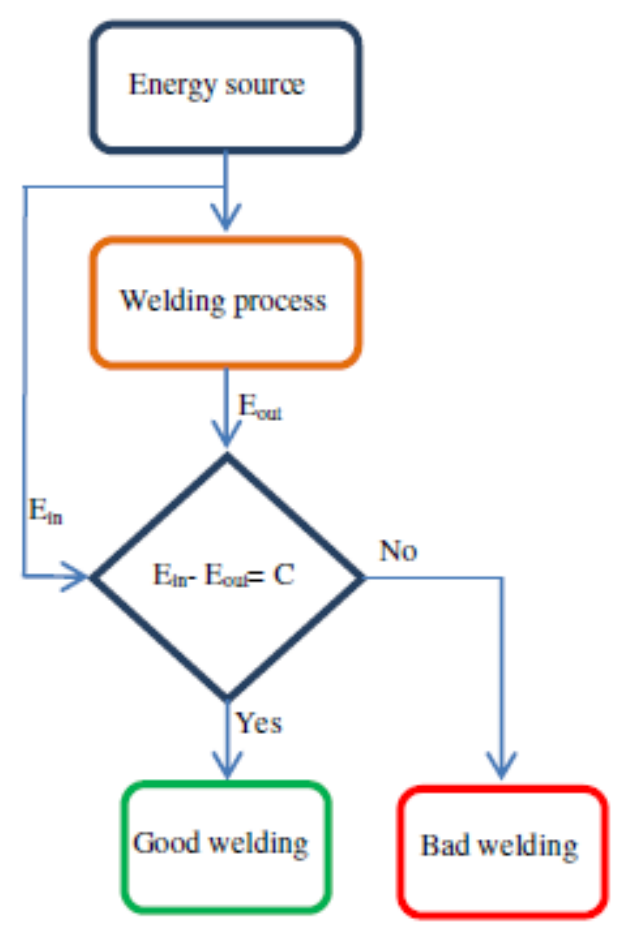

Figure 4 - Process signature block diagram [6].

The energy source is an ultrasonic voltage signal generator, which supplies the excitation to ultrasonic actuator. The actuator transmits mechanically the vibration to sonotrode that will rub the parts that must be welded. This generator supplies all information about the energy generated to execute the welding by RS232 computer communication.

The device, called as sonotrode, can be composed by two sections, a mother and daughter(s). This last item can be composed by more than one termination which could weld various similar parts simultaneously.

The welding process is the time which the parts are rubbed, in ultrasonic vibration, one to the other, until both parts to be melted and the interface to be completely bonded. This motion must be continuously and uniform. During the welding process the vibration that pass through the parts excites the lower device and this energy can be measured. This lower device is responsible to hold the body part of the MFR which stays steady at all time. 
Then, had collected all data, the comparison will be possible and it is going to made by a computer, installed beside of the welding equipment, the data compared are acquisition of the power spent for the ultrasonic generator, the remaining vibration. This way, it is possible to compute the residual energy that results from the process, which provides information about the bonded that was done.

Finally, after analysis done by computer, it is able to show the result about the welding, approving or disapproving it.

\section{EVALUATION METHODS}

Most of the tests to evaluate plastic welding are destructive, where the parts cannot be used again. In this way, can be mentioned the pull off force of the welded parts, where the purpose, in this kind of experiments, is to detach the welded parts and quantify the force and its profile. The disadvantages about this method are that the MFR cannot be used after that and in addition, it is not possible to guarantee that the parts were homogeneously attached. So, it is not possible to ensure the MFR leakage, but, in the other hand it can measure the average adherence.

The Figure 5 helps to see that the pull off force is a good measurement of adherence where both lateral caps were welded by the same process and presented no leak.

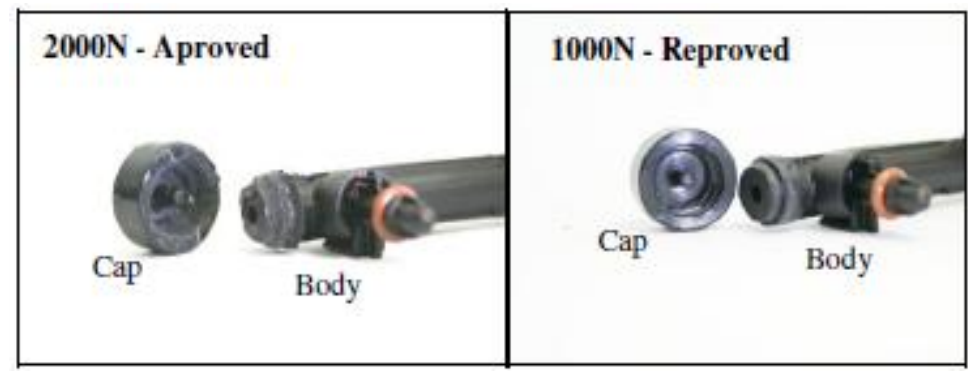

Figure 5 - Good and bad welded caps [6].

As we can see on Figure 5, the approved one has several signs that the parts were well attached. The reproved MFR shows a poor or small adherence area which can allow a detachment during normal operation.

The force profile, acquired during the pull off test, can illustrate some characteristics too. Find examples of profiles in Figures 6 and 7. 


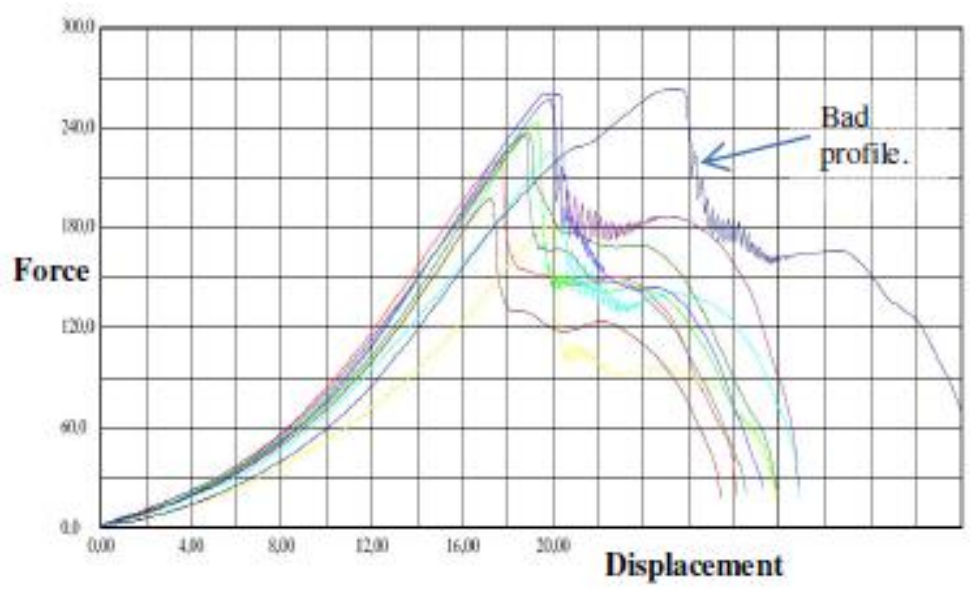

Figure 6 - Pull off force profile example 1 [6].

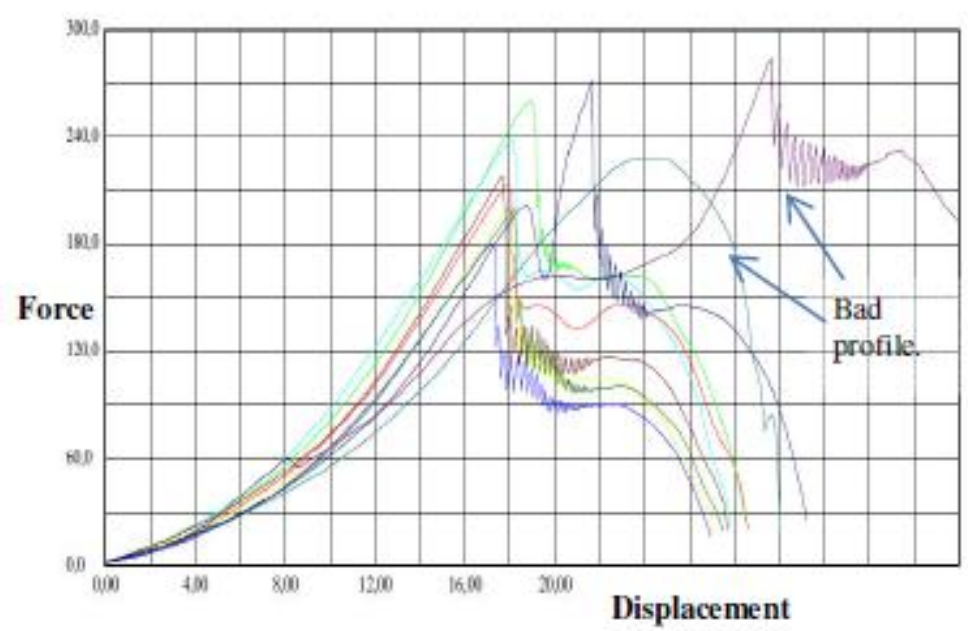

Figure 7 - Pull off force profile examples 2 [6].

In addition, an important technique, called plastography, was developed by Magneti Marelli Physical-Chemical Lab team. The name was chosen for its similarity with metallography [4]. Basically the technique involves making transversal slices of the attached parts to see the interface.

The method used here was to cut the fuel rail cap in four (4) segments equally, like the Figure 8 scheme. This way, the welding interface is possible to be observed in different sections like can be seen on diagram bellow. 

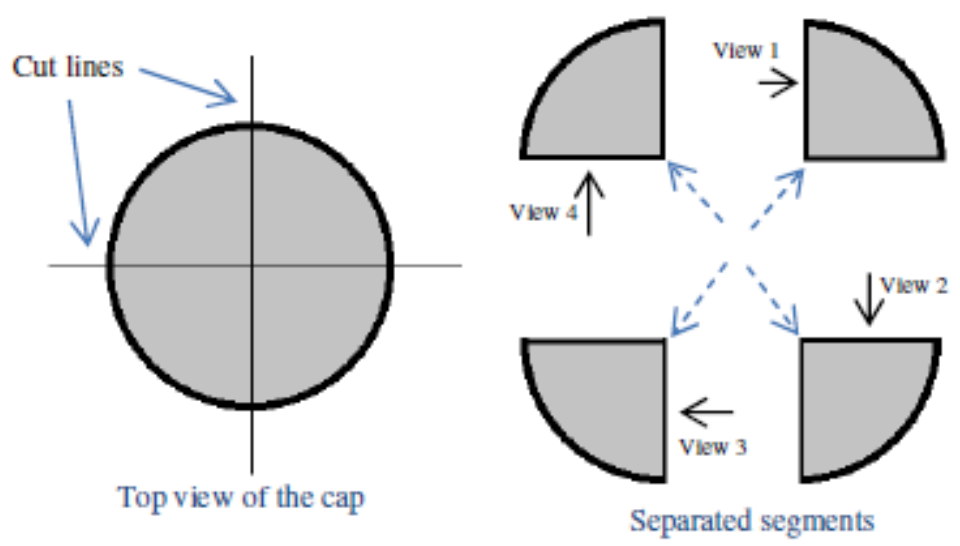

Figure 8 - Parts preparation to plastography [6].

After the separation, all segments are put in a resin (similar to metallography [4]) and polished together. Then, the setup is exposed to the microscope and the interface is visualized, as exposed on Figure 9 and Figure 10, where each Figure shows all four (4) views of the same welding interface. The cap is on the lower side of the picture and the MFR body is on the upper side. 


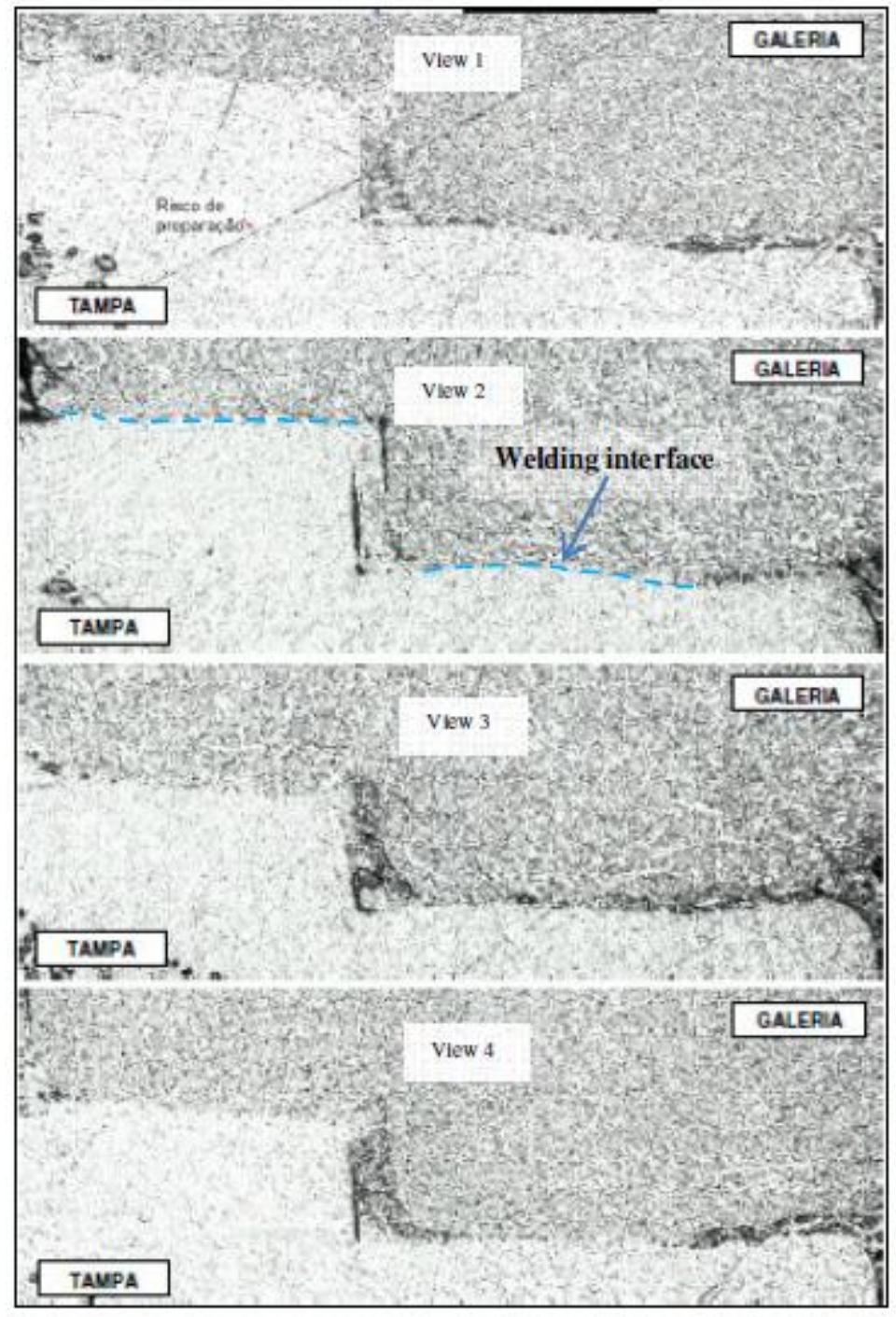

Figure 9 - Good welded parts plastography [6].

The Figure 9 shows an approved welding by plastography, or better saying, no discontinuity was found. On the Figure 10, one bad welding is configured by a nonhomogeneous interface between cap and MFR body, see the indication, mainly on view 2 and view 4. These discontinuities allow some leak enough to reprove parts. 


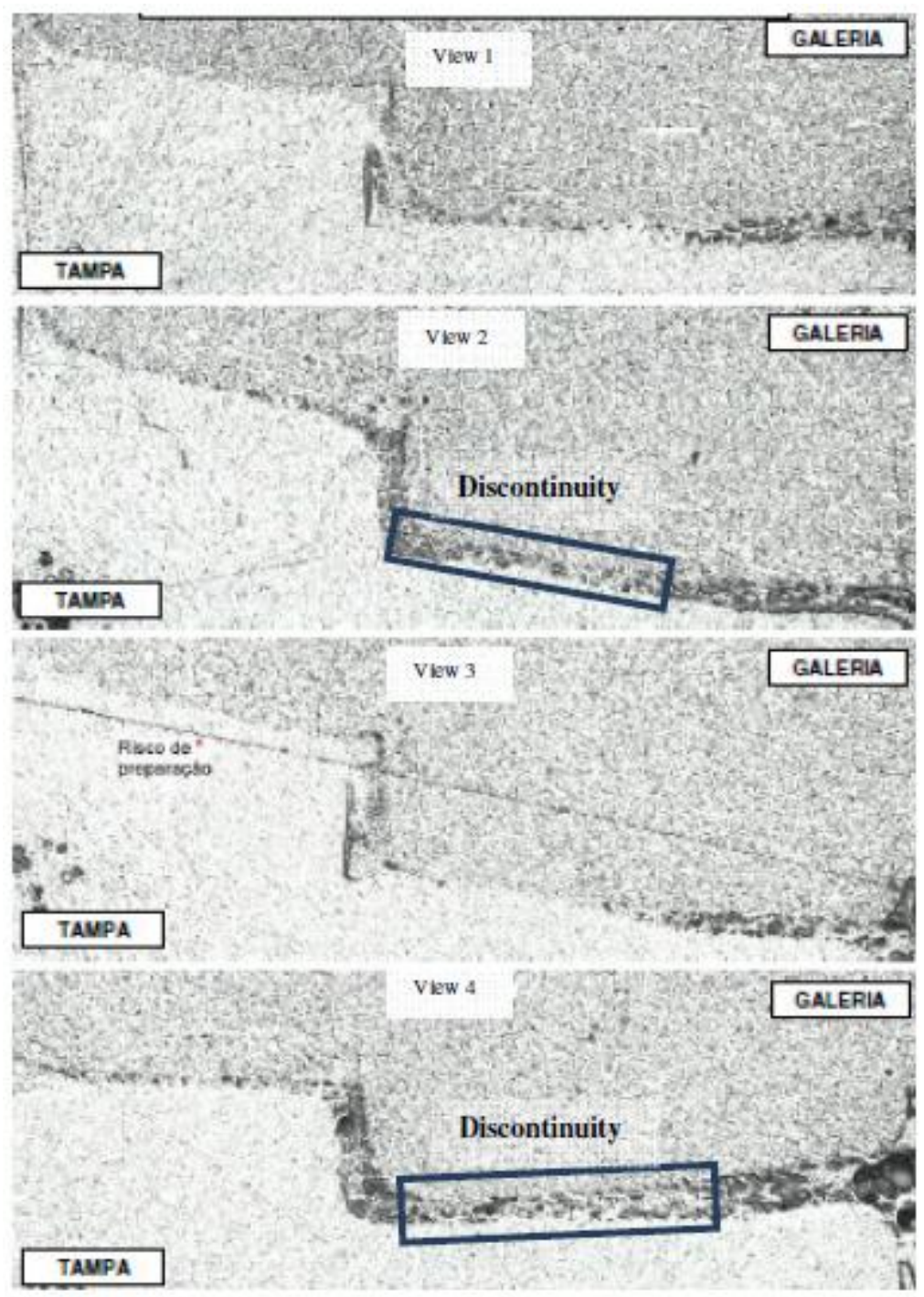

Figure 9 - Bad welded parts plastography [6].

Besides being a destructive technique, the plastography is able to evaluate only on the cut position and to be sure that all interface is good, many slices should be performed. Because this and all equipment used for, this technique takes some time and is expensive, useful for a development or a deep investigation, but not to a quality control.

A third method to test the welding is the leakage by pressure drop of a known volume or an accurate flow rate meter which are possible using just commercial equipments, available in many models and manufacturers. These equipments are a good way to test and avoid the leakage, however, it will be necessary to test the complete assembled MFR or to do a test after each operation. If the idea is to eliminate operations or scrap, both approaches are not so recommended and in addition, the leakage test does not measure the real bonding parts adherence and its susceptibility to mechanical stresses.

All of those shown techniques are useful in some part of development. All of them combined can produce a good tool to evaluate a welding quality but, is not possible to use any one or all together, to have a production line quality control. 
Looking for a final quality and product functionality, during its life, the development tests were made in MFRs thermal aged. This rule allowed to have a more reliability results due it accelerates and evidences aspects after some thermal exposure.

All of these methods, cited in this item, are named here like reference methods (RM).

\section{WELDING SIGNATURE}

The process signature developed here consists of a parameters combination which gives the welding quality estimation and these parameters were tuned using statistics tools and comparing with those RM cited before. So, the RM were used to validate the Welding Signature (WS).

The concept is measure all variable involved in the welding process and discover what is important to do a good welding. After several welded parts was observed that to do a good welding was necessary to generate an identified energy range. Find on the Figure 10 the energy distribution supplied by the ultrasonic source $\left(\mathrm{E}_{\mathrm{in}}\right)$ to weld several parts.

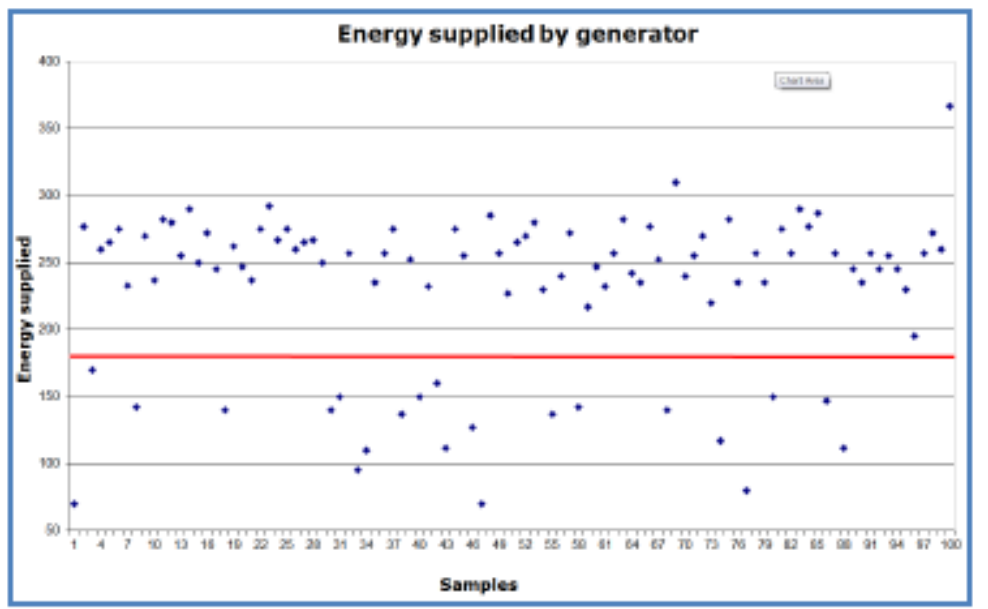

Figure 10 - Energy supplied by the source $\left(\mathrm{E}_{\mathrm{in}}\right)[6]$.

The parts above of red line, are reproved at least one of evaluation method. In the other hand, some parts into the range are also reproved for some RM.

Thinking about the phenomena which is responsible to do the welding is clear that the energy spent on process is significant to identify if it was a good or a bad welding. But, to quantify the real energy spent to weld, it is not enough to get the energy generated to "shake" the parts, it is necessary to measure how many energy was dissipated and not transmitted in the interface.

That energy dissipation, is in fact, a conversion from kinetic to thermal energy, when the parts are rubbed, melting this way a particular layer of the material and if this conversion was done in a homogeneous way in both welded parts, the attachment shall be reliable.

It is possible to quantify how much energy was converted thru temperature measurements [1] [2]. But, it is not accurate and takes long time stabilization. Like this energy is inserted in the set by a vibration method, a fast and precise measurement of the remaining energy was done using an accelerometer, like exposed on Figure 11. The generator supplies energy in a well 
formatted mode, allowing its identification and if the vibration is measured near to the welded parts, as shown on Figure 11 it can acquire fraction of the remaining vibration that flows though welded parts.

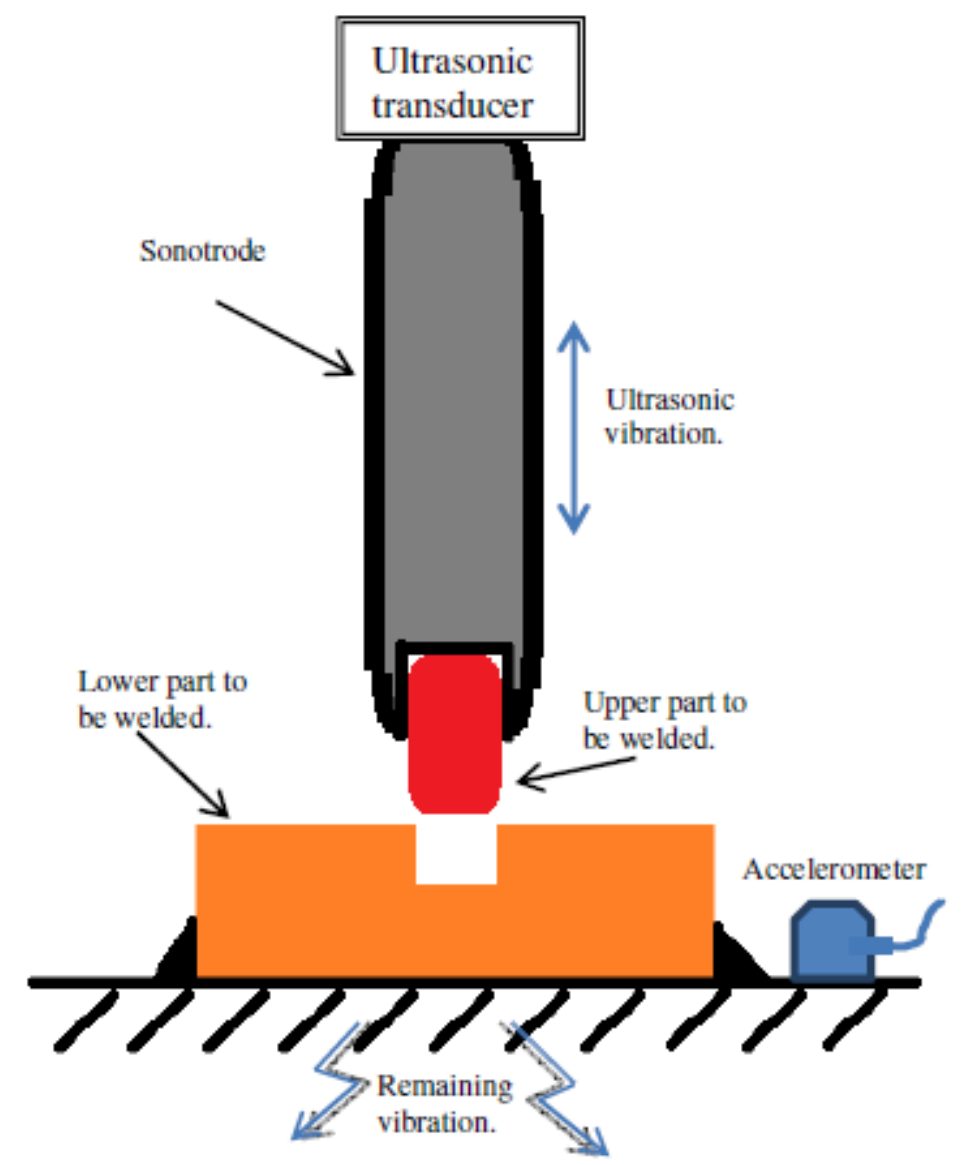

Figure 11 - Welding scheme and measurement arrangement [6].

Like can be seen in the scheme above, the idea is to compare the supplied $\left(\mathrm{E}_{\text {in }}\right)$ and the remaining $\left(\mathrm{E}_{\text {out }}\right)$ energies by measuring the vibration. This way, it is possible to classify the welding by its energy consumption.

Find on Figure 12 a chart of the vibration energy, for the same pieces set of the Figure 10, which had its remaining vibration energy levels $\left(\mathrm{E}_{\text {out }}\right)$ registered too. 


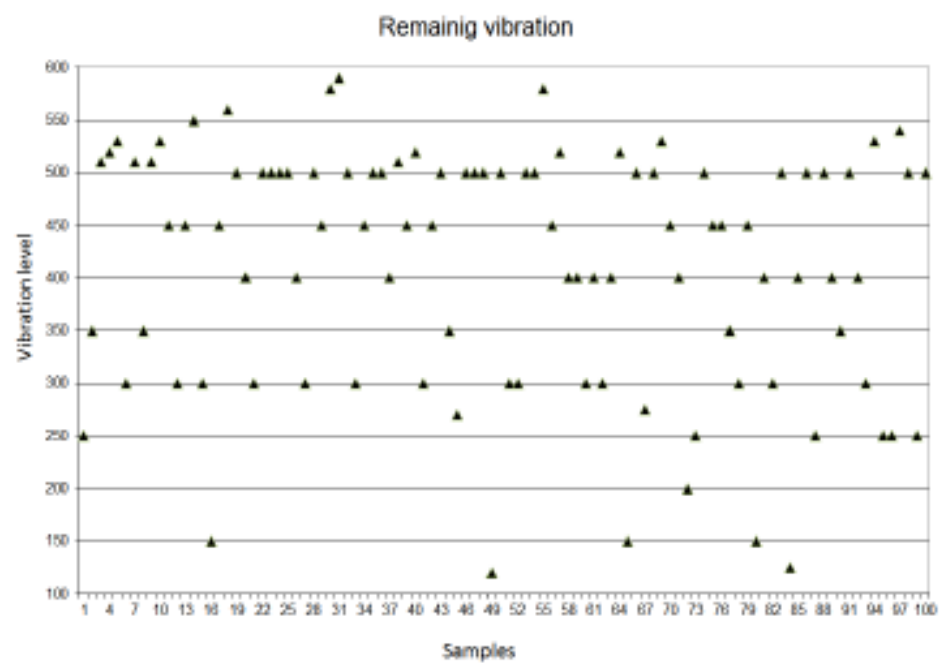

Figure 12 - Remaining vibration energy $\left(\mathrm{E}_{\text {out }}\right)[6]$.

Observing the remaining energy $\left(\mathrm{E}_{\text {out }}\right)$, on Figure 12, and comparing with the generated one ( $E_{\text {in }}$ - figure 10), it is possible to create an arrangement of a good energy relation which classify the welding by the spent energy. It is shown on Figure 13, the resulting welding energy, calculated by the delta between energies $\left(E_{i n}-E_{o u t}\right)$, for the same pieces set.

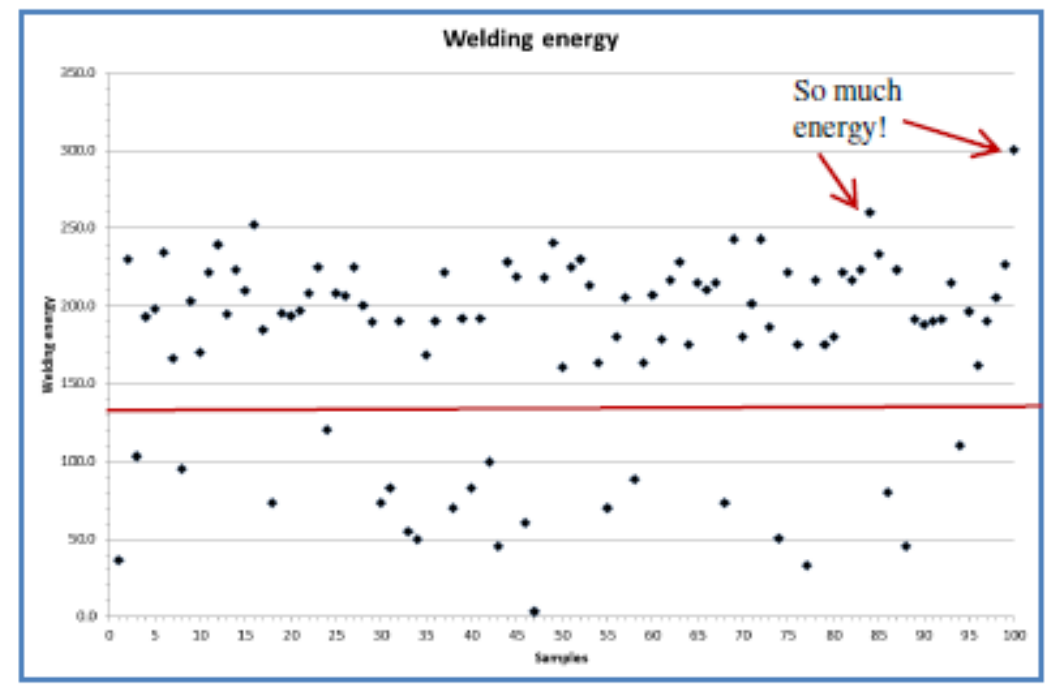

Figure 13 - Real energy spent to weld parts [6].

It is easy to see, in the Figure 13, that there are two well defined groups. The parts bellow the red line, were reproved by at least one RM.

Two parts were classified like "So much energy", because the elements were deformed, these elements were welded and the final MFR did not leak but, the process melted a great amount of material and the final result was the MFRs dimensions out of specifications. This way, it was decided to specify a cut off line for a maximum value too.

Other relations and parameters can be monitored and used to evaluate devices like the sonotrodes or the lower device. Find on the additional benefits section, some information about it. 


\section{WELDING SIGNATURE}

To demonstrate the methodology efficiency two hundred (200) parts were submitted to the welding process and after that, these parts were exposed to thermal aging and finally, evaluated by RM to validate the WS.

The incoherence encountered was only six MFRs reproved by the WS which were approved by RM. It is considered a good result, due the security factor which can ensure that no bad part will be assembled.

\section{CONCLUSION}

With this work, have been out stretched a new study line for ultrasonic welding and it is told a new one, because it was necessary to develop and improve devices, instruments and sensors to do measurements in this scope, promoting so, an innovative know how about ultrasonic measurements and plastic's welding.

The WS efficiency has reached the desired level, showing that is possible to do an on line quality control for plastic's welding which is increasingly a critical process, creating many opportunities for this technique application.

\section{REFERENCES}

[1] BALBINOT, Alexandre; BRUSAMARELLO, Valner. Instrumentação e Fundamentos de Medidas - volume 1.

[2] BALBINOT, Alexandre; BRUSAMARELLO, Valner. Instrumentação e Fundamentos de Medidas - volume 2.

[3] BARRON, Randall. Vibration Signature Analysis. Monash University, Melbourn, 1974. [4] BRAMFITT, Bruce; BENSCOTER, Arlan. Metallographer's Guide - Practices and Procedures For Irons And Steels.

[5] BARRON, Randall. Industrial Noise Control Acoustics.

[6] CAVAGLIERI, Marcelo; FIGUEIREDO, Filipe; CARDIA, Fabiano; REIS, Geraldo.

Plastic welding process signature. SAE Brasil 2012, 2012.

\section{DEFINITIONS}

$\mathbf{E}_{\mathbf{i n}}-$ Energy generated to actuate and interact with the parts to be welding;

$\mathbf{E}_{\text {out }}-$ Residual energy from the welding process;

Fifth injector - It is an additional electronic fuel injector used to drive the CSS;

MFR - Mini FuelRail; 
MI - Mini Injector;

PA66 + 30\% FG - Is a polymer (nylon) with 30\% of fiber glass. The polyamide $6 / 6$ is one of the most versatile engineering thermoplastics. It is popular in every major market using thermoplastic materials. Because of its excellent balance of strength, ductility and heat resistance, nylon 6/6 is an outstanding candidate for metal replacement applications. Nylon $6 / 6$ is very easy to process with a very wide process window. This allows it to be used for everything from complex, thin walled components to large thick walled housings;

Plastography - Similar to the metallography consists to microscopy observation of the plastic welding interface. The welded parts are cut in a way that the melted interface can be evaluated and discontinuities detected. It is a technique developed in Magneti Marelli by its actuation field, producing many items in plastic like fuel rail and intake manifolds;

Quality factor - Is a factor that describes the resonance sharpness. It is calculated by the ratio, between object natural frequency and its bandwidth [5].

$\mathbf{R M}$ - Reference methods is a set of procedures to ensure the MFR reliability. This set is composed by Leak test, Pull off force/profile and Plastography. All of done after thermal aging exposure;

Sonotrode - Device that transmits the vibration to parts which must be welded. Thermal aging - For this study was used a thermal exposure where parts stay during $24 \mathrm{~h}$ in a $120^{\circ} \mathrm{C}$. 